Aus der Chirurgischen Abteilung des Städtischen Krankenhauses in Schleswig und dem Hygienischen Institut in Kiel (Direktor: Prof. Kißkalt).

\title{
Bacterium enteritidis Gaertner als bakteriologischer Befund bei Gallenblasenentzündung.
}

Von Dr. Boehm und Prof. Dr. Ludwig Bitter.

Als Erreger der Cholezystitis acuta kennen wir Strepto- und Staphylokokken, Bacterium coli, Typhus- und Paratyphus-BBakterien. Bacterium enteritidis Gaertner ist als Erreger schwerer Gallenblasenentzündung bisher nicht beobachtet. Es soll daher in Kürze über einen derartigen Fall berichtet werden, der im Städtischen Krankenhause Schleswig zur Beobachtung und Operation kam und im Hygienischen Institut Kiel bakteriologischätiologisch identifiziert wurde.

Frau Th., 43 Jahre alt, aufgenommen 9. Januar 1919. Leidet seit 14 Tagen an Durchfällen, hat sich aber dabei bisher ganz wohl gefühlt. Am 8. Januar mittags plötzlich heftige Leibschmerzen und mehrfaches Erbrechen. Wird am 9. Januar fruh dem Krankenhause uberwiesen, hier am 10. Januar mittags von der Inneren auf die Chirurgische Abteilung verlegt.

Vorgeschichte: Immer blutarm, seit zehn Jahren magenleidend, mußte regelmäßig nach dem Essen erbrechen, auch hin und wieder wegen starker Magenschmerzen das Bett , hüten. Typhus oder länger dauernde Durchfälle will sie früher nie gehabt haben.

Befund: Sehr elendes Aussehen, Puls 92, klein, Temperatur $36,0^{\circ}$ rektal. Zunge belegt. Leib im Oberbauch, besonders rechts und in der Mitte, sehr druckempfindlich, ausgesprochene défense musculaire, die jede Abtastung verhindert. Leichter Meteorismus. Unterbauch frei. - Kein Ikterus, Urin frei von Eiweiß und Zucker.

Sofortige Operation wegen Verdacht auf schwere Gallenblasenentzündung oder abgekapselte Magenperitonitis.

Aethertropfnarkose $(200 \mathrm{~g})$

Schnitt parallel dem rechten Rippenbogen. Magen gebläht Gefäße an der Pars pylorica und am Querkolon mächtig injiziert, strotzend gefüllt. Magen und Duodenum frei von Veränderungen. Rechter Leberlappen stumpfrandig, stark geschwollen. Gallenblase ziemlieh stark gefallt, zart; einige strangförmige, ödematöse Adhåsionen von ihr zum Querkolon und Netz werden durchtrennt. Punktion entleert eigenartig schmutzig-trabe

1) Virch. Arch. 148 S. 439 
Galle. Schnitteröfnung zeigt die Gallenblase frei von Steinen, ihre Schleimhaut etwas geschwollen. Wegen des schlechten Allgemeinzustandes muß von der Ektomie abgesehen werden: Zystostomie mit fingerdickem Drain. - Punktionsflüssigkeit wird an das Hygienische Institut zu Kiel eingesandt.

Verlauf: In den ersten drei Tagen schwerer Kollapszustand mit kaum fühlbarem, aber nur wenig beschleunigtem Puls $(74-92)$ und tiefer Temperatur $\left(36,3-37,1^{\circ}\right)$. Nase spitz und kühl. Patientin macht den Eindruck einer Moribunden. Unter Infusionen, Heißluftkasten und Exzitantien, langsame Besserung. Am fünften Tage Durchfall, dadurch wieder Verfall schwerster Art, von dem sich Patientin nur langsam erholt. Gallenabsonderung anfangs spärlich, später sehr reichlich, Gallenblasenfistel schließt sich langsam. Entlassen am 1. März 1919.

Nachuntersuchung 14. April: Patientin sieht frisch aus, "Magenbeschwerden" sind verschwunden. Narbe noch etwas empfindlich.

Epikrise: Bei einer 43 jährigen Erau bestehen seit zehn Jahren "Magenbeschwerden" mit häufigem Erbrechen nach dem Essen. Nach 14 tägigem Durchfall ohne Störung des Allgemeinbefindens plötzlich schwere Erkrankung mit heftigen Schmerzen im Oberbauch und Verfall bei tiefer Temperatur und wenig erhöhter Pulszahl. Die Operation ergibt 48 Stunden später starke Blutüberfüllung der Nachbarorgane der Gallenblase, die selbst auffallend wenig Veränderungen zeigt außer strangförmigen Adhäsionen mit Netz und Querdarm. Im Punktat Bacterium enteritidis Gaertner. Nach Cholezystostomie sehr langsame Rekonvaleszenz unter tagelang anhaltendem schweren Kollaps.

Die jahrelang bestehenden „Magenbeschwerden" sind wohl durch die alten Verwachsungen an der Gallenblase ausgelöst worden und durch deren Beseitigung verschwunden: Ganz ähnliche Erscheinungen sahen wir kürzlich bei einem kräftigen Mann nach Exstirpation der sehr kleinen, zarten, durch Adhäsionen sanduhrförmig veränderten Gallenblase sofort aufhören. Die Infektion mit Bacterium enteritidis Gaertner, für die eine Quelle nicht festzustellen ist, hat offenbar nach 14 tägigem Darmkatarrh die Gallenblase ergriffen. Sie führte in der steinfreien Gallenblase $\mathrm{zu}$ einem Krankheitsbilde, das durch ungewöhnlich schweren Kollapszustand, vor und nach der Operation bei tiefer. Temperatur und wenig beschleunigtem, sehr kleinem Puls charakterisiert war und durch Ableitung der infizierten Galle in Heilung überging.

Das am 13. Januar 1919 im Untersuchungsamte für ansteckende Krankheiten eingetroffene Gallenpunktat wurde auf Chinablauagar (Bitter) und Blutagar ausgesät. Im direkten Ausstriche fanden sich ganz vereinzelte Gram-negative Stäbchen. Die 18 Stunden bebrüteten Schalen zeigten üppiges Wachstum, und zwar grauweißlicher, saftiger, mittelgroßer, rundlicher Kolonien ohne Hämolyse auf Blutagar, und farbloser, ziemlich großer, runder auf dem Chinablaunährboden. Nach weiteren 24 Stunden, während welcher die Chinablauplatte bei Zimmertemperatur aufbewahrt wurde, hatten sich die auf ihr befindlichen Kolonien mit einem schönen Schleimwall umgeben. Die von der 18 Stunden alten Schale angelegten Kulturen in Traubenzuckerneutralrotagar, Chinablaumolke (Bitter), Peptonwasser zeigten der Reihe nach folgendes Verhalten: Gasbildung und Verłärbung, starke Bläuung, Trübung und nachträgliche Entfärbung, keine. Indolbildung. Die von der Chinablauagarschale außerdem angelegte Reinkultur auf Schrägagar wurde durch Typhusimmunserum (Titer $1: 2000$ ) in der Verdünnung $1: 500$, von Paratyphus-B-Serum (Titer $1: 2000$ ) in der Verdünnung $1: 100$, vom Gaertner-Serúm (Titer 1.20000 ) bis zum Endtiter innerhalb zwei Stunden bei Brutofentemperatur makroskopisch agglutiniert. Mikroskopisch präsentierten sich die isolierten Bakterien als gut bewegliche, Gram-negative, durchweg mittelgroße Stäbchen. Die mit in Reinkulturaufschwemmung getauchten Brotstückchen gefütterte Maus starb am achten Tage. In ihrem Herzblut wurde das gleiche Stäbchen mit allen beschriebenen Merkmalen in Reingleiche Stäbchen mit allen beschriebenen Men
kultur und in großen Mengen nachgewieser.

Es dürfte mithin keinem Zweifel unterliegen, daß in dem eingesandten Gallepunktat Stäbchen vom Typus des Bacterium enteritidis Gaertner vorhanden waren, denen, da keine anderen Mikroorganismen neben ihnen gefunden wurden, man mit allergrößter Wahrscheinlichkeit die ätiologische Bedeutung für die bestehende schwere Gallenblasenentzündung zuschreiben muß. Ob die 14 Tage vor dem Manifestwerden dieser Entzündung beobachteten Durchfälle als eine durch diesen Fleischvergifter bedingte frische Infektion aufzufassen sind, an die anschließend sich in so ungewöhnlich kurzer Zeit die Gallenblasenaffektion entwickelte, scheint zweifelhaft, aber nicht ganz ausgeschlossen. Wahrscheinlicher dürfte die Annahme sein, daß die Bakterien schon längere Zeit in der Gallenblase bzw. in den Gallengăngen der Patientin vorhanden gewesen sind.

Der mitgeteilte bakteriologische Befund dürfte zu den großen Seltenheiten gehören. 